\title{
LAVAGEM DE DINHEIRO E CRIMES CONTRA A ADMINISTRAÇÃO PÚBLICA
}

\author{
MONEY LAUNDERING AND CRIMES AGAINST PUBLIC ADMINISTRATION
}

Rafael Diniz Pucci*

\begin{abstract}
Resumo:
A lavagem de capitais assume diferentes facetas, conforme a conduta desviante que a precede. Uma das condutas precedentes está relacionada à Administração Pública e corrupção. O sistema brasileiro de controle da lavagem de capitais é híbrido, porquanto combine às práticas de harmonização judiciais e legislativas, também mecanismos de controle e cooperação no âmbito executivo.

Palavras-Chave: Lavagem de Dinheiro. Branqueamento de Capitais. Ocultação de Bens e Valores. Direito Penal Econômico. Regulação Financeira.

Direito Sancionador. Separação de Poderes. Crimes contra a Administração Pública.
\end{abstract}

\begin{abstract}
:
Money laundering gets different facets, according to the deviant behavior that precedes it. One of the preceding conducts is related to the public administration and corruption. The Brazilian money laundering control system is hybrid and combines the practices of legislative and judicial harmonization with mechanisms of cooperation inside the executive power.
\end{abstract}

Keywords: Money laundering. Criminal Economic Law. Financial Regulation. Sanctioning Law. Separation of Powers. Crimes against public administration.

\section{Introdução}

A partir década de 1980, impulsionado pelo incremento significativo da circulação de capitais trazido pela revolução tecnológica informacional.' o fenômeno da lavagem de dinheiro foi objeto recorrente de estudos, pesquisas e questionamentos. ${ }^{2}$

A ordem normativa internacional, então, foi significativamente alterada, principalmente no campo da regulamentação da atividade financeira, do combate ao crime

Doutor em Direito Penal pela Faculdade de Direito da Universidade de São Paulo. Ex-bolsista do Programa PET/Capes, financiado pela Sesu/MEC.dinizpucci@yahoo.com.br.

1 Para detalhes da relação entre os impactos da globalização no campo do direito, ver FARIA, José Eduardo. O Direito na Economia Globalizada. São Paulo: Malheiros, 1992.

2 Veja-se, neste sentido, ALBRECHT, Hans-Jörg. Criminalidad transnacional, comércio de narcóticos y lavado de dinero. Bogotá: Universidad Externado, 2001. 
organizado e do terrorismo. ${ }^{3}$ Com efeito, diplomas normativos internacionais surgiram no âmbito das Nações Unidas (de modo paradigmático a Convenção de Viena de 1988, bem como a Declaração de Princípios de Basileia, do mesmo ano) e também, no âmbito União Europeia, as convenções traçadas no Conselho da Europa na década de 90, dispondo sobre lavagem de capitais.

Paradigmáticas, ainda, foram as Recomendações traçadas pelo Grupo de Ação Financeira (GAFI ou FATF, Financial Action Task Force), criado em Paris pelo G-7 em 1989. O Brasil formalizou sua adesão ao GAFI no ano 2000.

Cite-se, ainda, a Organização dos Estados Americanos, OEA, que, em1992, por ocasião de sua XXII Assembléia Geral, publicou Regulamento Modelo cuidando da lavagem de dinheiro e delitos a ela relacionados, principalmente no que tange ao tráfico de entorpecentes e outros delitos de grande impacto.

As empresas ligadas a práticas de lavagem de capitais, especialmente instituições financeiras, também têm sinalizado com medidas supostamente de combate ao ilícito. No entanto, não é possível precisar até que ponto encontram-se dispostas a reduzirem seus lucros e mercados, para contribuírem para a redução das condutas desviantes. Certo é que os códigos de condutas e políticas financeiras de tais instituições têm incluído regras cujo intuito é o de coibir a lavagem.

2. Sistema brasileiro de controle da lavagem de dinheiro

No âmbito legislativo, a par do output operado pelas transformações da ordem normativa internacional, o sistema brasileiro de combate à lavagem de dinheiro foi engendrado a partir da Lei n. 9.613/98. Certo é que o sistema encontra-se em vias de sofrer mudança, tendo em vista o Projeto de Lei n. 209/2003 do Senado, que na Câmara recebeu o n. 3.443/2008.

No poder executivo, a criação do COAF (Conselho de Controle de Atividades Financeiras) - no Ministério da Fazenda - e também do Departamento De Recuperação de Ativos e Cooperação Jurídica Internacional - do Ministério da Justiça marcou as políticas do executivo, no que tange principalmente ao estabelecimento e estímulo de um modelo de cooperação para recuperação de ativos advindos de operações fraudulentas de lavagem de capitais. De se mencionar, ainda, a criação da Estratégia Nacional de Combate à Corrupção e à Lavagem de Dinheiro (Enccla), da qual fazem parte diversas instâncias governamentais, comportando o Gabinete de Gestão Integrada de Prevenção e Combate à Lavagem de Dinheiro (GGI-LD).

3 ALBRECHT, Hans-Jörg. Criminalidad transnacional, comércio de narcóticos y lavado de dinero. Bogotà: Universidad Externado, 2001. 
No judiciário, varas especializadas foram criadas e algumas decisões causaram impacto nacional na matéria, a exemplo das proferidas na $6^{\mathrm{a}}$ Vara Criminal da Justiça Federal de São Paulo, que ganhou visibilidade nacional e internacional.

Além disto, o Banco Central do Brasil, a partir de Cartas Circulares, tem estabelecido diretivas para as instituições financeiras com o intuito de orientá-las no combate às práticas de lavagem de capitais.

O presente artigo procurará explorar uma das principais facetas do crime de Lavagem de Dinheiro, qual seja, o fato de que um dos bens jurídicos ofendidos por tal tipo é a Administração Pública.

Autores há que, ao cogitar do Bem Jurídico subjacente à Lavagem de Dinheiro, defendem a idéia de pluriofensividade, vale dizer, a Lavagem de Dinheiro representaria, por si mesma, ofensa a mais de um Bem Jurídico, delimitados, via de regra, por: 1) Administração Pública; 2) Ordem Sócio-Econômica; 3) Patrimônio; 4) Bem Jurídico protegido pelo crime antecedente.

O tipo Favorecimento Real, previsto pelo Código Penal que em seu artigo 349 estatuiu que: "Prestar a criminoso, fora dos casos de co-autoria ou de receptação, auxílio destinado a tornar seguro o proveito do crime: Pena - detenção, de 15 (quinze) dias a 3 (três) meses, e multa" parece ser o ponto inicial da discussão no ordenamento pátrio.

Evidente os tipos em questão, lavagem de dinheiro e favorecimento real tutelam bens jurídicos diversos, porém, "em termos conceituais podem ser vistos como tipos paralelos, um referido à aplicação de penas e medidas de segurança a pessoas, outro referido ao confisco de bens", nas palavras de Godinho. ${ }^{4}$

Para Castellar, "o que basicamente diferencia o crime de favorecimento real do crime de lavagem de dinheiro é o tipo subjetivo de cada um desses delitos, uma vez que, como vimos, no primeiro caso basta a vontade do agente de prestar o auxílio ao criminoso, com o fim de assegurar-lhe o proveito do crime, enquanto que na lavagem, mais do que isso, a intenção do agente deve ser a de, além de ocultar o produto do crime cometido por terceiros, dar-lhe a aparência idônea, reintegrando-o no mercado como se tivesse sido obtido licitamente, isto é, fazendo a chamada "engenharia financeira"' s

4 GODINHO, Jorge Alexandre Fernandes. Do crime de branqueamento de capitais. Introdução e Tipicidade. Coimbra: Almedina, 2001. p. 246.

5 CASTELLAR, João Carlos. Lavagem de dinheiro. A questão do bem jurídico. Rio de Janeiro: Revan, 2004. p. 165. 
Certo é que a Lavagem de Dinheiro foge ao âmbito dos delitos clássicos contra a propriedade individual, dada a sua relevância ${ }^{6}$ que, nas palavras de Caparrós, assume contornos coletivos. ${ }^{7}$

No caso em questão, da Lavagem de Dinheiro proveniente de crime contra a Administração Pública, a definição estatuída pela Lei n. 9.613/1998 é elucidativa, em seu artigo 1o., V, ao definir, nos seguintes termos: "crime contra a Administração Pública, inclusive a exigência, para si ou para outrem, direta ou indiretamente, de qualquer vantagem, como condição ou preço para a prática ou omissão de atos administrativos" 8

Há que se ter presente, ainda, o disposto no art. 11, parág. $2^{\circ}$ " "as comunicações de boa fé, feitas na forma prevista neste artigo, não acarretarão responsabilidade civil ou administrativa"

Não menos importante, o disposto no art. 11, parág. $3^{\circ}$ "as pessoas para as quais não exista órgão próprio fiscalizador ou regulador farão as comunicações mencionadas neste artigo ao Conselho de Controle das Atividades Financeiras - COAF e na forma por ele estabelecida"

O Conselho de Controle das Atividades Financeiras - COAF - é órgão subordinado ao Ministério da Fazenda. Tem por função, consoante a Lei n. 9.613/1998, "disciplinar, aplicar penas administrativas, receber, examinar e identificar as ocorrências suspeitas de atividades ilícitas previstas nesta Lei, sem prejuízo da competência de outros órgãos e entidades" sendo certo que "das decisões do COAF relativas às aplicações de penas administrativas caberá recurso ao Ministro de Estado da Fazenda"

\section{Separação de poderes}

As Funções do Estado encontram-se divididas em Legislativa, Judiciária e Administrativa, o que parece decorrer da separação de poderes. Tais funções estariam distribuídas em três blocos orgânicos denominados poderes, que teriam em si uma das três funções predominantes ${ }^{9}$ Esta construção política, que muitas vezes não encontra respaldo na realidade, onde as funções se misturam, é atribuída ao Barão Charles Secondat Montesquieu, que a idealizou com a finalidade de "impedir a concentração de poderes para preservar a liberdade dos homens contra abusos e tiranias dos governantes"

\footnotetext{
6 Veja-se GÁL, István László. The techniques of money laundering. In: GÁL, István László et. al. (Ed.), Emlékkönyv, Losonczy István Professzor Halálának 25. Évfordulójára: Pécs, Auctoritate Universitatis Pécs Publicata, 2005. p. 129 e ss.

7 CAPARRÓS, Eduardo A. Fabián. El delito de blanqueo de capitales. Madrid: Editorial Colex, 1998. p. 183.

8 Lei n. 9613/1998, art. 1, V.

9 MELLO, Celso Antônio Bandeira de. Curso de direito administrativo. 24. ed. São Paulo: Malheiros, 2007. p. 29-31.
} 
Assim, para Montesquieu, haver-se-ia de dividir o exercício das funções entre os diferentes órgãos de Poder, a fim de se compor os freios e contrapesos, "mecanismo por força do qual atribuindo-se a uns, embora restritamente, funções que em tese corresponderiam a outros, pretende-se promover um equilíbrio melhor articulado entre os chamados 'poderes" isto é, entre os órgãos do Poder, pois, na verdade, o Poder é uno" 10

Parece consensual a idéia de que a Administração Pública, no exercício de sua Função Administrativa, tenha por escopo o alcance do interesse público, utilizando-se das competências que a lei lhe outorga. A única disputa que pode surgir é quanto ao caráter desta função - Bandeira de Mello, por exemplo, afirma constituir tal função um dever."

Neste sentido, Regis Prado pondera que conquanto seja a função administrativa prerrogativa primordialmente do Poder Executivo, é ela "exercida atipicamente pelos Poderes Judiciário e Legislativo no que tange à sua estruturação e funcionamento" 12

Consoante ensina Paulo José da Costa, tal distinção "permite-nos compreender adequadamente por que os crimes contra a administração pública não se limitam tão-somente a condutas delituosas praticadas contra a atividade do Poder Executivo, ou no interior dos quadros onde este atua" 13

\section{Administração Pública}

Regis Prado conceitua como "estado-administração" o "conjunto de órgãos" destinados à "satisfação coletiva de bens e serviços ... para executar tais atividades direta ou indiretamente ou simplesmente fiscalizar o seu exercício" 14

O Princípio da Separação de Poderes constituiria, pois, "mero critério de distinção das atribuições operacionais, no âmbito interno da unidade da soberania estatal. Conseqüentemente, o termo Administração Pública deverá ser entendido em sentido lato, de modo que compreenda todos os sujeitos e toda a atividade peculiar aos poderes estatais, ou a qualquer outro órgão ou ente institucional" "15 Neste sentido, também seriam agentes

10 MELLO, Celso Antônio Bandeira de. Curso de direito administrativo. 24. ed. São Paulo: Malheiros, 2007. p. 32 .

$" \quad$ Id. Ibid., p. 29.

12 PRADO, Luiz Regis. Curso de direito penal brasileiro. 5. ed. São Paulo: Revista dos Tribunais, 2008. v. 3, p. 421.

13 COSTA JUNIOR, Paulo José; PAGLIARO, Antonio. Dos crimes contra a administração pública. São Paulo: Malheiros, 1999. p. 13.

14 PRADO, Luiz Regis. Curso de direito penal brasileiro. 5. ed. São Paulo: Revista dos Tribunais, 2008. v. 3, p. 421.

is COSTA JUNIOR., Paulo José; PAGLIARO, Antonio. Dos crimes contra a administração pública. São Paulo: Malheiros, 1999. p. 13. 
de atos administrativos o Legislativo e o Judiciário, porquanto, por exemplo, tenham servidores e os administrem.

O Legislativo tem função jurisdicional, por exemplo, quando julga o Presidente da República, assim como o Executivo, por exemplo, quando do processo administrativo. O Judiciário tem função de produção normativa, quando estabelece regimentos e regulamentos, assim como o Executivo, na hipótese de iniciativa legislativa e poder de veto.

Assim que conclui Paulo José da Costa ser a atividade administrativa - para além de não aplicada exclusivamente pelo Executivo - a "atividade na qual se expressa o exercício da função administrativa, isto é, a função de execução das normas jurídicas" 16

Paulo José da Costa entende ainda que se deve entender o conceito de Administração Pública sob duas perspectivas: primeiro, "o conjunto de agentes estatais, inclusive entidades da administração indireta, dotadas de personalidade jurídica de direito privado, aos quais seja atribuída função administrativa, qual seja, o desempenho de atividade administrativa" segundo, "a partir de perspectiva de atividade estatal que compreende o desempenho da função de execução das normas jurídicas, tendo em vista a realização dos fins da organização estatal" 17

\section{Administração Pública e o Direito Penal}

Ao revés do que ocorre no Direito Constitucional e no Direito Administrativo, em que o conceito de Administração Pública tem sentido restrito, limitando-se à atuação do Estado nos quadros da divisão de poderes, no Direito Penal, conforme Régis Prado, "a Administração Pública engloba toda a atividade estatal, tanto no sentido subjetivo, que significa os órgãos instituídos pelo Estado para a concreção dos seus fins, como no sentido objetivo, consistente na realização de toda atividade estatal visando à satisfação do bem comum" ${ }^{18}$ Esta teoria adota o partido da unidade estatal, "alcançando as funções exercidas pelos três poderes"

Assim, "os crimes previstos no presente título trazem como traço comum o atentado à atividade funcional do Estado" Paulo José da Costa enfatiza: "O código penal não entende por administração pública apenas a atividade administrativa em sentido estrito, distinta da atividade legislativa ou jurisdicional. Muito ao contrário, o código penal leva em consideração toda a atividade estatal, num sentido subjetivo e noutro objetivo. Sob

16 COSTA JUNIOR., Paulo José; PAGLIARO, Antonio. Dos crimes contra a administração pública. São Paulo: Malheiros, 1999. p. 13.

17 Id. Ibid., p. 15.

18 PRADO, Luiz Regis. Curso de direito penal brasileiro. 5. ed. São Paulo: Revista dos Tribunais, 2008. v. 3, p. 421. 
a angulação subjetiva, a administração pública é entendida como o conjunto de entes que desempenham funções públicas. Sob o aspecto objetivo, considera-se como administração pública toda e qualquer atividade desenvolvida para satisfação do bem comum. Em outras palavras: em direito penal, administração pública equivale a sujeito-administração e atividade administrativa" 19

Neste sentido, Mendes de Almeida aponta que "os delitos (contra a Administração Pública) constituem violação do interesse público no sentido mais amplo possivel", 20

Com efeito, em direito penal o conceito de administração pública compreenderia a atividade funcional do Estado e demais entes públicos (concepção unitária do Estado, com denominador comum na função pública) o que poderia ser visto como negação ao princípio da separação de poderes.

É que não somente a atividade administrativa em stricto sensu seria objeto de tutela penal, mas também a atividade administrativa em sentido lato proveniente das esferas legislativa e judiciária.

No que diz com o bem jurídico, "crimes contra a administração pública têm como característica comum aquela de ofender a atividade funcional do estado ou de outros entes públicos. O modo específico da ofensa pode apresentar-se, contudo, diverso entre um crime e outro. Conseqüentemente, a propósito de cada figura criminosa, será necessário especificar qual o objeto específico da tutela penal" 21

De todo modo, resta claro que o bem jurídico tutelado nos crimes contra a administração pública, diz com questões atreladas principalmente à "normalidade funcional, à probidade, ao prestígio e ao decoro da administração pública" 22

\section{Ilícito Penal e Ilícito Administrativo}

Paulo José da Costa, citando Cretella Jr., pondera que o ilícito é categoria jurídica que divide-se em penal, civil e administrativa, sendo que a diferença entre uns e outros reside no plano quantitativo ou de grau, e não no plano qualitativo ou de substância. ${ }^{23}$ Isto demonstra que o critério de oportunidade e conveniência, ligado ao interesse público é o que prevalece na decisão sobre qual é o ilícito, eis que ilicitude e dever jurídico é um só.

19 COSTA JUNIOR., Paulo José; PAGLIARO, Antonio. Dos crimes contra a administração pública. São Paulo: Malheiros, 1999. p. 16.

20 ALMEIDA, Fernando Henrique Mendes de. Dos crimes contra a administração pública. São Paulo: Saraiva, 1955. p. 9.

21 COSTA JUNIOR., Paulo José; PAGLIARO, Antonio. Dos crimes contra a administração pública. São Paulo: Malheiros, 1999. p. 18.

22 Id. Ibid., p. 18.

23 Id. Ibid., p. 19. 
Para o autor, "ao lado do ilícito penal praticado pelo funcionário público, há também o ilícito administrativo, com sanções específicas, podendo ocorrer, por conseguinte, a cumulação de reprimendas (penal e administrativa) ao mesmo caso concreto" Ainda, "no que tange à diferença entre ambos, inclusive no que tange às sanções, não é ontológica e sim apenas de grau, de quantidade", ${ }^{24}$

Diz Regis Prado que quando o ato praticado "denota maior gravidade, ferindo substancialmente o interesse público, tutela-se o bem jurídico no âmbito do Direito Penal, enquanto aquele ato que não se reveste de maior importância é apenado administrativamente" 25

Certo é que a decisão emanada do juízo penal a respeito do mesmo caso também decidido em sede administrativa prevalece sobre esta, não impedindo, todavia, a condenação administrativa.

Paulo José da Costa adota posição aparentemente divergente, mas conclui de modo semelhante, pois, em sua opinião, há "prevalência do juízo penal sobre o juízo administrativo. Vale dizer, absolvido o funcionário público no juízo criminal pela prática de determinado delito que se lhe atribuiu, não poderá ele vir a ser condenado pelo mesmo delito em processo administrativo. Ou então, condenado anteriormente em processo disciplinar, vindo a ser absolvido no juízo penal, terá o funcionário direito à restitutio in pristinum" ${ }^{26}$ Todavia, diz o autor "o funcionário absolvido no juízo penal pelo crime pode ser condenado no administrativo pela falta disciplinar. Exemplo: absolvido pela prevaricação, nada obsta a que fique caracterizado o minus consistente na desídia ou no retardamento de ato de ofício" Concluindo que "podem constituir crimes contra a administração somente aqueles fatos que, além de ofenderem a atividade funcional do Estado ou de outros entes públicos, sejam previstos como crimes pela lei penal ... se o fato for previsto como ilícito tanto pela lei penal quanto pelo direito administrativo, aplicar-seão ao agente, conjuntamente, a sanção penal bem como a sanção administrativa" ${ }^{27}$

Conclusão

Consoante demonstrado, uma das principais facetas do crime de Lavagem de Dinheiro é o fato de que um dos bens jurídicos ofendidos por tal tipo pode ser a Administração da Justiça, em sede de crime antecedente. O fato de os Projetos de Lei em

${ }^{24}$ COSTA JUNIOR., Paulo José; PAGLIARO, Antonio. Dos crimes contra a administração pública. São Paulo: Malheiros, 1999. p. 19.

25 PRADO, Luiz Regis. Curso de direito penal brasileiro. 5. ed. São Paulo: Revista dos Tribunais, 2008. v. 3, p. $309-310$

26 COSTA JUNIOR., Paulo José; PAGLIARO, Antonio. Dos crimes contra a administração pública. São Paulo: Malheiros, 1999.p. 20.

27 Id. Ibid., p. 20. 
tramitação no Congresso (209/2003 do Senado e 3443/2008 da Câmara dos Deputados) excluírem o rol de crimes antecedentes não traz, em termos fáticos, alterações substanciais à punição da Lavagem de Dinheiro que tem como antecedente ato atentatório contra o bem jurídico Administração Pública.

O Brasil adotou, em seu Sistema de Controle da Lavagem de Dinheiro, modelo híbrido de controle. Com efeito, o ordenamento jurídico brasileiro contempla mudanças provenientes de regulamentação internacional (não apenas aquelas de direito cogente, ou seja, aquelas que por força da adesão a tratados e demais diplomas internacionais, o país é obrigado a adotar, mas também normas provenientes de diplomas soft law). Além da harmonização legislativa, o país adotou também, principalmente com a criação no âmbito executivo do COAF, do Departamento de Recuperação de Ativos e Cooperação Internacional e do ENCLA, mecanismo de cooperação com outros Estados, como modo de aperfeiçoar o sistema.

São Paulo, abril de 2010.

Referências

ALBRECHT, Hans-Jörg. Criminalidad transnacional, comercio de narcóticos y lavado de dinero. Bogotá: Universidad Externado, 2001.

MELLO, Celso Antônio Bandeira de. Curso de direito administrativo. 24. ed. São Paulo: Malheiros, 2007.

BERMEJO, Mateo Germán; VILLAR, Pacífico Rodríguez. Prevención del Lavado de dinero en el sector financiero. Buenos Aires: Ad Hoc, 2001.

CAPARRÓS, Eduardo A. Fabián. El delito de blanqueo de capitales. Madrid: Editorial Colex, 1998.

CASTELLAR, João Carlos. Lavagem de dinheiro. A questão do bem jurídico. Rio de Janeiro: Revan, 2004.

CONSEJO GENERAL DEL PODER JUDICIAL. Prevención y represión del blanqueo de capitales. Madrid: Ministerio de Economía, 2001.

CONSELHO DA JUSTIÇA FEDERAL, CENTRO DE ESTUDOS JUDICIÁRIOS. Uma análise crítica da lei dos crimes de lavagem de dinheiro: série pesquisas do CEJ. Brasília: Secretaria de Pesquisas e Informação Jurídicas, 2002.

CANAS, Vitalino, O Crime de branqueamento: regime de prevenção e de repressão. Coimbra: Almedina, 2004.

COSTA JUNIOR, Paulo José; PAGLIARO, Antonio. Dos crimes contra a administração pública. São Paulo: Malheiros, 1999. 
DUARTE, Jorge Manuel Vaz Monteiro Dias. Branqueamento de capitais. O Regime do D.L. 15/93, de 22 de janeiro, e a normativa internacional. Porto: Publicações Universidade Católica, 2002.

FARIA, José Eduardo. O direito na economia globalizada. São Paulo: Malheiros, 2002.

GÁL, István László. The Techniques of Money Laundering. In: GÁL, István László et al. (Ed.). Emlékkönyv, Losonczy István Professzor Halálának 25. Évfordulójára: Pécs, Auctoritate Universitatis Pécs Publicata, 2005.

GODINHO, Jorge Alexandre Fernandes. Do crime de branqueamento de capitais. Introdução e Tipicidade. Coimbra: Almedina, 2001.

MENDES DE ALMEIDA, Fernando Henrique. Dos crimes contra a administração pública. São Paulo: Saraiva, 1955.

PALACIOS, Fernando Eguidazu; PASTOR, Daniel Alvarez. La prevención del blanqueo de capitales. Pamplona: Editorial Aranzadi, 1998.

PRADO, Luiz Regis. Curso de direito penal brasileiro. 5. ed. São Paulo: Revista dos Tribunais, v. 2008. v. 3. 